\title{
On the Fusion and Value Discovery of Heterogeneous Non-conventional Big Data
}

\author{
Yong-mei, $\mathrm{He}^{1,2}$ \\ Guizhou University of Finance and Economics \\ 1. Institute of Finance \\ 2. Guizhou Institute of urban economy and development \\ Guiyang City, Guizhou Province, China \\ 411740421@qq.com
}

\author{
Hong-mei, Zhang ${ }^{1,2}$ \\ Guizhou University of Finance and Economics \\ 1. Institute of Finance 2. Guizhou Institute of urban \\ economy and development \\ Guiyang City, Guizhou Province \\ 2569055506@qq.com
}

\begin{abstract}
With the advent of big data era, the application of big data technology has aroused the concern of all walks of life. Finance is the core of modern economy, and data assets are the core assets of finance. Therefore, the deep integration of big data technology and finance plays an extremely important role in the new ecological and financial structure of our country. This paper introduces the current situation and trend of big data in the financial field, and analyzes the development path of heterogeneous financial data, and probes into the potential value of the development of financial big data.
\end{abstract}

Keywords-Big data; data assets; heterogeneity; financial innovation;

\section{INTRODUCTION}

Financial big data refers to the deep integration of inclusive finance and big data technology. Since 2011, the term "big data" has been widely quoted in western countries such as the United States, and has gradually become the focus of discussion in western countries and the hot topic discussed in academia. In 2013, "big data" was introduced into the research fields of finance, physics, biology and environmental ecology in China as academic terms, big data is constantly influencing the development of industry, technology and finance. As an important part of informational assets, data assets are mainly planned and managed by mining a large amount of data assets, forming a unique informational data asset management system. Fully tap out the value of the data needed to enable innovation in financial products and customer services, optimize internal management, and enable data-driven financial innovation ${ }^{[1]}$.

\section{THE Fusion DEVELOPMENT OF FinANCIAL BIg DATA}

At present, the application of big data in the financial industry is getting more and more attention. After the rapid development of big data in recent years, the development of big data has made great achievements. However, some problems remain due to the very new application of big data technology and the uneven application of big data by technical staff in various financial institutions. How to analyze and process large amount of data acquired, what data should be used for different products and activities, how to use the result of big data technology analysis and treatment to promote the innovation of business and products, At present, the application of big data in

The successful completion of this thesis is inseparable from the support and help of Insurance workstations of Guizhou University of Finance and Economics School of Finance. financial institutions mainly focuses on "risk control" and "three-dimensional marketing".

In recent years, big data technology has gradually been applied to financial services, and big data occupies an extremely important position in China's financial services. For example, big data technology has been widely used in alipay, mobile payment and crowd funding, and has gradually become an irreplaceable part of daily life. In the meantime, the ecommerce platform relies on the emerging technological advantages of big data technology and uses its huge data resources to carry out financial innovation and gradually increase its competitiveness in the financial field. Since 2012, financial services with big data technology as the core have started to emerge, accumulating a large amount of financial data resources. In 2013, with the rapid development of Internet finance, businesses such as Alibaba, YuBaoBao and Tencent swiftly seized the market. The competition in financial markets has become extremely fierce ${ }^{[2]}$. Various fund companies and P2P network lending companies have conducted business through the Internet. At the same time, this series of changes have forced the traditional financial industry represented by banks to speed up the pace of adaptation to the times and business innovation, and accelerate the industrial upgrading and the transformation of the operational model. In order to win the market, we must take advantage of the large amount of data resources accumulated over the long term, use big data technology to analyze and process, and establish a network financial service platform to improve our competitiveness.

\section{The DeVElopment Trend of FinAnCial Big DatA}

With the application of big data technology, more and more financial industry has also started to devote them to big data application practice. Research shows that the development of big financial data will bring about the following changes: First, machine learning will become an inevitable trend. At the same time, anti-fraud and risk control areas will also use more sophisticated technologies to improve the wind-control model itself and will accelerate the development of real-time analysis monitoring and early warning; Second, due to the large number of data large, updated quickly, such as data management, blood and other regulatory compliance issues will be more deeply integrated into big data platform, in order to meet compliance requirements, many financial institutions have adopted the 
single point solution. Or the use of obsolete traditional solutions platforms, none of these solutions meets the current large-scale development of data. At present, a lot of improvement project of Hadoop data management, the data is larger than the capacity of the traditional platform do, speed is more bitter, basic can meet the requirements of compliance and in detail, in order to achieve the goal of fusion supervision and risk control; Third, the financial sector will use physical network data to development of the Internet of things has developed to a mature in many industries, and accumulated a large amount of data resources, these industries drive the needs of Internet data and monopoly ${ }^{[3]}$. As a result, banks may be able to use IoT data for ATM or mobile banking and these are worth exploring in many channel real-time data streams; Fourth, the integration of financial big data and portfolio management, international trade and consulting applications has become a prominent feature of software suppliers. Big data platform to provide the core is to provide a bridge, and to create a sharp edge; Fifth, risk control and regulatory data management will become the core tasks of the financial big data platform, and the growth and user center related business behaviors will become the primary strategic goal of financial institutions, Risk control and regulation are the primary challenges for the financial sector, regardless of whether the bank is a well-developed data-driven company that is constantly changing the rules or facing a number of challenges $^{[4]}$.

\section{The Potential VAlue of Fusion DeVelopment of FINANCIAL BIG DATA}

The main difference between financial big data analysis and traditional data analysis is that there is model training for big data analysis. After machine learning, analysis and prediction are done again to make recommendations. The big data is the valuable data asset of the financial industry, how to find the value of data? First of all, the data should be analyzed, the value of data should be tapped through analysis, and the value should be tapped to carry out the ultimate goal of business innovation, product innovation and service innovation. Through the efficient integration of financial big data, we can improve efficiency, save costs and increase profits ${ }^{[5]}$. We can also increase revenue through precision marketing, like insurance, through financial big data, and we can also innovate financially by controlling risk and forecasting or modeling.

Victor wrote in the age of big data, The big data era will bring three changes: First, we can get more data, even can analyze and deal with the all the data of a particular phenomenon, rather than relying on the traditional technology of random sampling, the data will be more comprehensive and accurate, which helps to find more details; Second, the volume of research data is huge, so you can ignore the accuracy of the data without obsession and pursuit of data, and will be more conducive to improving our insight and greater commercial interests. Third, big data pay more attention to the correlation between things, instead of emphasizing the causality of things. Big data has changed the business intelligence can only rely on the present situation of the enterprise internal business data, under the technical support of big data, data sources are more diverse, in addition to the enterprise internal data, also includes the enterprise external data, especially the related data and consumers.

The fusion development of big financial data can obviously improve the accuracy and timeliness of financial data. It can also reduce the transaction friction cost between enterprises. Big data to help enterprise analysis, on the other hand, a large number of financial data for further mining niche market opportunities, eventually be able to shorten the financial product development time, improve enterprise innovation in business models, products and services, can significantly enhance the level of enterprise business decisions and reduce the risk of enterprise operation.

\section{The Challenges of Big FinANCIAL DATA}

\section{A. Data growth is fast, integration is more difficult}

As one of the characteristics of big data is the growth rate is very fast, geometric growth, the current global data volume of various industries the rate of appreciation is very rapid. At present, China's key areas such as finance, transportation and telecommunications, as well as key areas such as social security and customs, and the continuous deepening of informationization are further giving birth to new and vast amounts of data. According to statistics, China's total data volume reached $1700 \mathrm{~EB}$ in 2015, up $90 \%$ year on year, and the figure is expected to exceed 8000EB by 2020. Taking banking as an example, the banking industry generates an average of 130GB of data with an average of 130GB of data, the highest data intensity of all industries. But in financial data in a split within the enterprise, business line, intelligence department, channel, risk departments, and other branches are often the real owner of the data, the lack of a smooth sharing mechanism, lead to huge amounts of data are often in a scattered and "sleep", while the financial industry has data "rich", but "stretched" when they really use.

\section{B. Security of financial data}

Finance is the lifeblood of the economy of a country. The safety and security of data in the financial industry should be given high priority. Security and privacy issues are extremely important issues in the development of big data. After a large number of timely collection of real-time and innocuous data, personal privacy will also be exposed. In fact, the meaning of big data security is more extensive. The threats to people are not limited to the disclosure of personal privacy. The targets of protection include not only big data itself but also knowledge gained through big data analysis ${ }^{[6]}$. As with other current information, financial big data faces security risks in storage, processing and transmission, including data management risks and data operation risks. There is a need for the protection of technical means, as well as the improvement of relevant laws and regulations and the self-discipline of financial market participants.

\section{Financial data standard specification formulation}

In order to realize the connectivity of financial data, two conditions must be met, among which interconnection is the standard of technical system, and communication is the 
standard of data system. Interconnection can require the system to use a standardized interface, and interoperability needs to be established around the industry chain to establish a cross-industry data standard structure. At present, the development of various industries has its own way for a long time, with high barriers between industries. Even industries such as banks, securities and insurance in the financial industry adopt different standards and abide by different industry norms. How to speed up the development of common key standards such as metadata, data exchange, data exchange, data quality, security and confidentiality is the key to big data construction.

\section{Cultivation of the relevant talent echelon}

Talent is the core element of enterprise development. Compared with other niche talents in the information technology, the development of large data of compound ability request is higher, need to master the computer software technology, and have knowledge of mathematics, statistics, etc, and application in the field of professional knowledge. At present, there is a big gap between the financial industry in complex talents, high-end data scientists and management personnel who can afford analysis and excavation.

\section{THE FUSION PATH AND IMPROVEMENT DIRECTION OF FINANCIAL BIG DATA}

The application of any technology is based on demand, and the application of big data finance is also derived from the business drive of finance industry. However, there is no uniform standard for the integration and development of financial big data. Taking the most representative bank in financial industry as an example, based on business-driven innovation, the integration of financial big data can be applied to precision marketing, risk control, Service innovation and product innovation in five areas.

\section{A. Precise marketing}

Under the impact of the Internet, banks in the internet age urgently need to acquire more user information, and then construct a user 360 stereoscopic portrait, and analyze the customer's spending habits and consumption preferences to accurately segment customer segments. Real-time Marketing and other personalized marketing wisdom.

\section{B. Risk control}

Through the integration of financial industry and big data technology, it is possible to unify the management of heterogeneous data and external credit information of multi- source within financial enterprises, so as to better improve the risk control system. Internal data integrity and security to protect the external user risk control.

\section{Improve management}

Through big data analysis method to improve management decision, provide reliable data support for management, make operators more efficient, agile, and more accurate.

\section{Service innovation}

Through the use of big data technology, improve the interaction with customers, increase user stickiness, provide value-added services for individuals and government, and continuously enhance the core competitiveness of financial enterprise business.

\section{E. Product Innovation}

Through high-end data analysis and integrated data sharing, it effectively interfaces with various financial products such as banks, insurance, trusts, funds and so on, enabling financial enterprises to learn from other fields and create new financial products.

\section{CONCLUSION}

In the age of Big Data, data has become an important factor of production. Today's financial industry needs not only to basic data storage records, more attention should be paid to the increasing structured data sources integration analysis, make its successful release of the data value, achieve financial business innovation, it has become the key factor to the success of the financial industry development in the future.

\section{REFERENCES}

[1] Xiaolin Gong, The problems and countermeasures of Internet financial regulation in China[J]. Financial and economic, 2013(10):11-13.

[2] Hu Yang, Internet Financial Risk Early Warning Based on Big Data Analysis[J]. Modern Management Science, 2014, 4(4):3-5.

[3] [Jingwen Hou, Gongxun Cheng, Service Innovation of China 's Financial Data in the Age of Big Data[J]. Finance and economics, 2015, 10(26):27-34

[4] Yabin Zhang, Lili Ma, Heterogeneous Demand in Big Data Era, New Industrialization of Networked Supply[J]. Economist, 2015, 8(44):44500.

[5] Wei Lin, Xiangbing Wang, Big Data Finance: Opportunities, Challenges and Strategies[J]. Financial and economic, 2016, 5(3):140-142.

[6] Jianyu Xiong, Research on the construction of Internet finance credit investigation system based on big data[J]. Financial research, 2016, 4(18):263-264. 